rocks, does nothing" to help the prospector, is made in forgetfulness of the exhaustive and well-illustrated "Catalogue of the Glossopteris Flora" which was published by the Trustees of the British Museum six years ago, partly with the view of helping the development of the coal-fields in India and the southern hemisphere, where the handbook is extensively used.

\section{S. H. BURBURY, F.R.S.}

$B Y$ the death of Mr. Samuel Hawksley Burbury, on August 18, at eighty years of age, we have lost an ardent worker in the domain of mathematical physics who did much to elucidate the mysteries of several problems in molecular dynamics. Mr. Burbury was the son of Mr. Samuel Burbury, of Leamington, and was born at Kenilworth in May, I83I. $\mathrm{He}$ was educated at Shrewsbury and St. John's College, Cambridge; he was Craven University scholar, Chancellor's medallist, Browne medallist, twice Porson prizeman, and fifteenth Wrangler and second in classical tripos, 1854 . He was called to the Bar at Lincoln's Inn in 1858 , but his new profession did not prevent him from continuing his mathematical studies, and he thus became one of the few workers in this country who have produced original mathematical investigations while engaged in duties other than that of a mathematical teacher.

Much of Mr. Burbury's work was done in collaboration with the late Rev. H. W. Watson, F.R.S., with whom he shared the joint authorship of treatises on "The Application of Generalised Coordinates to the Dynamics of a Material System" (I879) and "The Mathematical Theory of Electricity" (1883-5), in the latter of which the authors endeavoured to place electrostatics and electromagnetism on a more formal basis than had been done by Clerk Maxwell in his original treatise. It is perhaps a pity that this book appeared at a time when experimental developments were beginning to break down many of our preconceived electrical theories, and, so far as we can gather, Watson and Burbury's treatise is not studied so much as it deserves. It affords a fairly satisfactory representation of electrical phenomena as known at the time, but, of course, every mathematical or dynamical theory of physical phenomena can only be regarded as a scheme for coordinating results of experiments in the simplest form; and with the discovery of new facts every such scheme is liable to be found inadequate when the necessity arises of superseding it by a more comprehensive scheme. It is thus probable that at the present time there is no scheme which represents our existing knowledge of electrical phenomena much better than Watson and Burbury's represented our knowledge at the time it was written.

But, like his friend Watson, Burbury seems to have chosen as his favourite study that branch of molecular dynamics in which Boltzmann occupied a central position. Burbury and Boltzmann were certainly in constant correspondence with each other, and many of Boltzmann's papers were evidently the result of Burbury's criticisms. Perhaps Burbury's training as a barrister gave him special qualifications for playing the rôle of critic; at any rate, if there was a weak point in any argument Burbury would certainly find it out in a very short time. A great amount of time was spent in examining Boltzmann's "Minimum Theorem," according to which an assemblage of molecules representing on the kinetic theory a perfect gas, tends to assume the distribution commonly known as "Maxwell's Law." In the proof of this theorem the question of reversibility plays an important part, and it cannot be said that the introduction of probability considerations altogether overcame the dithculty of accounting for an irreversible phenomenon by means of a system the elements of which were subject to the equations of motion of reversible dynamics.

In his "Kinetic Theory of Gases" (I899), Burbury advanced a novel theory as to the distribution of velocities in a medium the molecules of which were too close together to satisfy the fundamental hypotheses involved in the proof of Maxwell's law. According to Burbury, the velocities of neighbouring molecules would become correlated, the probability factor involving, besides the usual exponential of the energy, the exponential of the vector product of the velocities of pairs of molecules. Burbury further offered, on this hypothesis, a tentative explanation of liquefaction. According to Burbury, Maxwell's law would thus become inapplicable to a dense gas. On the other hand, if applied to rare gases, it leads to the conclusion that helium and hydrogen cannot escape from the earth's atmosphere, a conclusion which the late Dr. Stoney stated was not in agreement with his observations. Thus the kinetic theory of gases affords another instance of a scheme which covered our knowledge of physical phenomena at one time but no longer does so. To overcome this difficulty we are now resuscitating kinetic theories, but employing them on a smaller scale than before-to electrons instead of molecules.

Another question which occupied Burbury, especially during recent years, was the loss of availability which occurs when two gases mix by diffusion of constant temperature. As Burbury argued, if this happens when different kinds of molecules mix by diffusion, the same thing should be true when molecules of the same kind mix by diffusion. Burbury's views on this subject were stated in Science Progress a few years ago. This problem again gave Burbury scope for his critical mind. It cannot be said, however, that he, or, indeed, anyone else, has succeeded in giving a reason why the total entropy of a litre of one gas and a litre of a second gas is equal to the entropy of the mixture when its volume is one litre, while if two litres of the same gas at the same pressure are allowed to mix, the sum of their entropies is equal to the entropy of the mixture when its volume is two litres. What Burbury really showed by his arguments was that the truth or otherwise of these statements can only be tested by experimental evidence.

At the present time the study of mathematical physics is rather out of fashion in this country, and it is not unusual to deprecate this study on the ground that it frequently fails to account for the results of observation. Is not this failure one of its most valuable features? Whenever a new physical phenomena is discovered, plenty of people are ready enough to invoke molecules, the æther or electrons, to account for it, and to talk about the motions of these which give rise to the observed phenomenon. The mathematical physicist comes along and says, "Very well; then let us write down the equations of motion and see if the reasoning works out correctly." He obtains a result which does not account for experimental conclusions. Which is wrong? Not the mathematician who has merely attempted to place the reasoning on an exact basis, but the unmathematical physicist who has endowed his ether molecules, his ether, or his electrons with properties that are incompatible with each other. In Mr. Burbury we have had a worker who never finched from the task of following a line of argument up to its logical conclusions, however much these might run counter to orthodox views. $\mathrm{He}$ would drive his, opponent from one stronghold to another, the controversy being conducted in the most friendly way the whole time. The contest would freNO. 2 I83, VOL. 87$]$ 
quently end in a truce, both sides agreeing that there was much in Nature that we could never understand. But Burbury was rarely the first to give in. It is these passages of arms which very often enable men to appreciate each other's good qualities, and to realise the useful part which men like Burbury may play in evolving order out of chaos.

G. H. BRYAN.

\section{PROF. A. LADENBURG.}

THE death occurred at Breslau, on August $1_{5}$, of Dr. Albert Ladenburg, professor of chemistry in the University of Breslau. Dr. Ladenburg was born at Mannheim in 1842 , and graduated as doctor of philosophy in 1863 . In 1873 he accepted an invitation to take up a position as professor of chemistry and director of the laboratory at Kiel. In 1886 the honorary degree of doctor of medicine of Berne University was conferred on Dr. Ladenburg in recognition of his scientific investigations, and British and other societies, including the Pharmaceutical Society of Great Britain, also honoured him with honorary membership. He was also awarded the Hanbury gold medal for his services in the promotion of research on the chemistry of drugs. It was in 1889 that Dr. Ladenburg took up the post of professor of chemistry at Breslau, and he occupied the office with very great success.

Ladenburg's name is best known by his synthetic work on the production of homatropine. On splitting up atropine, tropic acid and tropine can be formed as derivatives; the latter Ladenburg combined with anygdalic acid to form a compound which is converted into oxy-toluyl-tropeine, or homatropine, an artificial alkaloid which, with its salts, has proved of the greatest service in ophthalmic surgery. His mathematical method of treating synthetic formulæ, and his prismatic benzene ring, place him in the first rank of chemists as a theorist; while as to his practical work, his list of communications to scientific societies and literature in this country and elsewhere includes articles on "The Valency of Nitrogen," on "Synthetic Alkaloids," on "The Relationship between Hyoscyamine and Atropine and the Conversion of the one Alkaloid into the other," on "Hyoscine," on "The Mydriatic Alkaloids occurring in Nature," on "The Svnthesis of Coniine," and on "The History and Constitution of Atropine," in addition to the compilation with other collaborators of a dictionary ("Handwörterbuch der Chemie"), consisting of thirteen volumes dealing with inorganic and organic chemistry.

\section{THE BRITISH ASSOCIATION AT PORTS- MOUTH.}

$\mathrm{B} Y$ the time this issue reaches the readers of Nature $B$ the eighty-first meeting of the British Association will have been inaugurated at Portsmouth, and, given fair weather conditions, we trust it will be a useful and enjoyable gathering. Judging from the number of distinguished men of science who have expressed their intention of being present, the meeting should be of importance as regards its scientific work, as well as successful from a social point of view.

The reception-room is the large Connaught Drill Hall, which appears to be ideal for that purpose. It gives under one roof a large reception hall with post office, telephone, \&c., and a comfortably furnished reading and writing room for the members. In addition to this there is also a small room set apart for the use of ladies.

In point of view of numbers, the Portsmouth meeting may not reach that of Sheffield last year, but this is accounted for partly by the absence of any specia! industry attached to the town, and also may, to some extent, be due to the absence of any university or university college. Most of the accommodation available is, however, booked, and those who arrive late mav have difficulity in finding quarters.

The meeting rooms are a little scattered, but this was unavoidable, and notices will be displayed making the routes to be taken to the various section-rooms easy to find.

In passing, mention may be made of a convenient plan for communication between members of the association. It is a box which will be placed in the reception-room, into which notes may be dropped addressed to other members. This box will be frequently cleared, and the notes delivered on request to those to whom they are written.

The pleasures of the meeting commence to-day (Thursday), when at 2.30 a party will be taken over the dockyard and battleships. A garden-party is to be given this afternoon by Sir John and Lady Brickwood at their beautiful residence in the town. In the evening the Mayor will give a reception at the South Parade Pier, which is the property of the Corporation.

On Friday afternoon there will be a special visit to the new filtration works of the Borough of Portsmouth Water Company, and Saturday will be entirely devoted to all-day excursions, including two to the Isle of Wight, and three drives in the South Downs, starting from Chichester, to which city there will be a special train. The drives are to (I) Kingly Vale, West Dean, and Goodwood; (2) Boxgrove Priory and Arundel Castle; (3) Bignor (with the Roman remains) and Parham Park.

On Sunday the Bishop of Winchester is to preach at the Portsea parish church, and on Tuesday the Mayor will entertain the members at a garden-party. In addition, the naval authorities have organised a naval display in Stokes' Bay, consisting of an attack by torpedo-boat destroyers and submarines. Visitors should not neglect a visit to the old Victory, one of the most interesting "links with the past" in existence, and a full description of which, written by Mr. W. L. Wyllie, R.A., will be found in an interesting little handbook to Portsmouth which will be presented to members.

Inaugural Address by Prof. Sir. William Ramsay, K.C.B., Ph.D., LL.D., D.Sc., M.D., F.R.S., PRESIDENT.

Ir is now eighty years since this Association first met at York, under the presidency of Earl Fitzwilliam. The object of the Association was then explicitly stated:- "To give a stronger impulse and a more systematic direction to scientific inquiry, to promote the intercourse of those whe science in different parts of the British Empire with one another and with foreign philosophers, to obtain a more general attention to the objects of science and a removal of any disadvantages of a public kind which. impede its progress."

In I83 I the workers in the domain of science were relatively few. The Royal Society, which was founded by Dr. Willis, Dr. Wilkins, and others, under the name of the "Invisible, or Philosophical College," about the year 1645 , and which was incorporated in December, I660, with the approval of King Charles II., was almost the only meeting-place for those interested in the progress of science; and its Philosophical Transactions, begun in March, I664-5, almost the only medium of publication. Its character was described in the following words of a contemporary poem :-

$$
\begin{aligned}
& \text { "This noble learned Corporation } \\
& \text { Not for themselves are thus combined } \\
& \text { To prove all things by demonstration, } \\
& \text { But for the public good of the nation, }
\end{aligned}
$$$$
\text { And general benefit of mankind." }
$$ 